\title{
Helminths of the brown rat (Rattus norvegicus) (Berkenhout, 1769) in the city of Palermo, Italy
}

\author{
C. MILAZZO ${ }^{1}$, A. RIBAS ${ }^{2}$, J. C. CASANOVA ${ }^{3}$, M. CAGNIN ${ }^{1}$, F. GERACI ${ }^{4}$, C. DI BELLA ${ }^{4}$
}

\begin{abstract}
${ }^{1}$ Department of Ecology, University of Calabria, Via P. Bucci s/n, 87036 Arcavacata di Rende (Cosenza), Italy, E-mail: c.milazzo@unical.it, cagnin@unical.it; ${ }^{2}$ Department of Population Biology, Institute of Vertebrate Biology, Academy of Sciences of the Czech Republic, CZ-675 02 Konesin, Studenec 17122, Czech Republic, E-mail: alexisribas@hotmail.com; ${ }^{3}$ Laboratory of Parasitology, Faculty of Pharmacy, University of Barcelona, Avda Diagonal s/n 08028 Barcelona, Spain, E-mail: jcasanovaia@ub.edu; ${ }^{4}$ Area di Sorveglianza epidemiologica, Istituto Zooprofilattico Sperimentale della Sicilia, "Via Marinuzzi Gino", 4, 90129 Palermo, Italy, E-mail: Francesco.Geraci@izssicilia.it, calogero.dibella@izssicilia.it
\end{abstract}

\begin{abstract}
Summary
A helminthological survey was performed on 143 brown rats (Rattus norvegicus) from the city of Palermo (Italy). The overall prevalence of helminth infection was $98.60 \%$. The following parasites were found: Brachylaima sp. (prevalence $8.39 \%$ ) (Trematoda); Taenia taeniaeformis larvae (11.89\%), Rodentolepis nana (13.29\%), Hymenolepis diminuta (24.48 \%) (Cestoda); Gongylonema sp., (4.90\%), Syphacia muris (8.39\%), Nippostrongylus brasiliensis (18.88 \%), Eucoleus gastricus (30.07 \%), Mastophorus muris $(30.77 \%)$, Capillaria hepatica $(54.55 \%)$, Heterakis spumosa $(82.52 \%)$ (Nematoda) and one acanthocephalan $(0.70 \%)$. The species found in males were also present in females, with the exception of the acanthocephalan. No significant differences were found between males and females in prevalence $(\mathrm{P} \%)$ or mean infection intensity (MI). However, a significant correlation between both $\mathrm{P} \%$ and MI, as well as host age, was observed in some helminth species. Hosts were infected by one to six helminth species (median $=3$ ). This is the first report from Sicily of helminths in $R$. norvegicus.
\end{abstract}

Keywords: Rattus norvegicus; wild brown rats; helminths; Sicily; Italy

\section{Introduction}

The helminths that parasitize rats are of special interest due to their role as reservoirs of human helminthiasis (GomezVillafane et al., 2008). Little is known about the helminth fauna of Rattus norvegicus in Italy and only two previous studies have ever been performed, both on the Italian mainland: one in Emilia Romagna and Toscana in northcentral Italy (Macchioni, 1967) and another in Rome in central Italy (Vanni, 1937). The present study aims to fill this gap and also to increase knowledge of the helminth fauna of $R$. norvegicus, a synanthrophic rodent that only established itself in the city of Palermo and on Sicily as recently as the twentieth century (Sarà, 1998).

\section{Materials and methods}

A total of $143 R$. norvegicus were studied for helminths in March - December 2004 in Palermo, the largest city in Sicily (Italy). Sixty-eight male and 75 female rats (122 adults and 21 juveniles) were collected and ages were assigned according to Delattre and Le Louar (1981) (adult rats $>130 \mathrm{~g}$, juvenile rats $<100 \mathrm{~g}$ ). Rats came from 17 sites in the town of Palermo: Ippomontato, Campo Nomadi, Cantiere Navale, Mattatoio comunale, Canile Privato, Mercato Ittico, Foce del Fiume Oreto, Via Spadafora, Via Bronte, Villa Niscemi, Istituto Sperimentale Zootecnico, V. Carrabia, Via Torrente d'inverno, Via Celona, Villa Garibaldi, Cartiera Pizzimenti and Quartiere Zen II (San Nicola).

The brown rats were trapped using Havahart traps with live bait. All the animals were then transported to the laboratory at the Istituto Zooprofilattico in Palermo and were killed by exposure to a $\mathrm{CO}_{2}$-saturated atmosphere. The viscera were separated and dissected in order to identify the helminths present. Trematodes and cestodes were stained with Semichon acetocarmine, dehydrated in alcohol, cleared in xylene and mounted in Canada balsam. Nematodes and acanthocephalans were mounted temporarily in Amann lactophenol. All the helminths were identified from their morphology and morphometry as per the literature. Capillaria hepatica (Bancroft, 1893) infections were diagnosed microscopically by the presence of the typical bi-polar eggs with a double layer shell and radial striations on the outer shell (Calle, 1961). The ecological terminology and quantitative parameters used were according to Bush et al., 1997.

The differences in parasite prevalences were tested using 
Chi-square tests $\left(\chi^{2}\right)$, while the Kruskal-Wallis test was used to establish differences in intensities for host sex and age. Prevalences were expressed as percentages and the $95 \%$ confidence interval (CI) was calculated. All statistical tests were calculated using SAS System 9.1 for Windows software.

\section{Results}

In all 9,343 helminth specimens were identified in 141 parasitized rats (Table I). The overall prevalence of gastrointestinal helminth infection was $98.60 \%$ (95\% CI: 94.52 - 99.76). Twelve helminth species were recovered: one trematode (Brachylaima sp.); three cestodes (Taenia taeniaeformis (Batsch, 1786) larvae; Hymenolepis diminuta (Rudolphi, 1819); Rodentolepis nana (Von Siebold, 1852); seven nematodes (Capillaria hepatica (Bancroft, 1893); Eucoleus gastricus (Baylis, 1926); Nippostrongylus brasiliensis (Travassos, 1914); Mastophorus muris (Gmelin, 1790); Gongylonema sp.; Syphacia muris (Yamaguti, 1941); Heterakis spumosa (Schneider, 1866); and one acanthocephalan. The only acanthocephala specimen found was damaged and unidentifiable to a major taxonomical level. Of the cestodes, Hymenolepis diminuta (24.48\%), and of the nematodes, Capillaria hepatica $(54.55 \%)$ and Hetera- kis spumosa $(82.52 \%)$, were the most prevalent helminth species. The infected animals hosted from one to six helminth species (average $=2.93$; median $=3$ ) with the following distribution: one species (14.90\%), two species $(25.53 \%)$, three species $(28.37 \%)$, four species $(16.31 \%)$, five species $(12.76 \%)$ and six species $(2.13 \%)$. There were no statistically significant differences between males and females in the either the prevalence or intensity of infection, or in mean intensities and total helminths.

Even though the number of young rats $(\mathrm{n}=21)$ and adults $(\mathrm{n}=121)$ examined was very different, it is still possible to make comparisons. In juvenile rats the prevalence of $\mathrm{Bra}$ chylaima sp. was higher than in adults (19.05 vs 6.56). In adult rats the prevalence of all nematodes except Gongylonema sp. (4.92 vs 4.76) and S. muris (8.20 vs 9.52) was higher than in juveniles. There were statistically significant differences in the prevalences in the age classes for $C$. hepatica (59.02 vs 28.57) $\left(\chi^{2}=6.69 ; P<0.05\right)$, E. gastricus (33.61 vs 9.52) $\left(\chi^{2}=4.93 ; P<0.05\right)$, M. muris $(34.43 v s$ 9.52) $\left(\chi^{2}=5.22 ; P<0.05\right)$ and $H$. spumosa $(85.25$ vs 66.57$)$ $\left(\chi^{2}=4.29 ; P<0.05\right)$. A significant difference in the mean intensity of parasite infection between the two age groups was observed for E. gastricus (10.27 vs 5.00) (test $\mathrm{H}=$ 4.93; $\mathrm{P}<0.05)$ and M. muris (5.52 vs 2.50) (test $\mathrm{H}=5.35$; $\mathrm{P}<0.05)$.

Table 1. Site of infection, number of infected hosts, number of parasites, prevalence (\%), upper and lower confidential limits at $95 \%$ significance, mean intensity $( \pm \mathrm{SD})$ and range of infection in 143 Rattus norvegicus captured in Palermo (Sicily, Italy)

\begin{tabular}{|c|c|c|c|c|}
\hline & Site & P\% & $\mathrm{MI} \pm \mathrm{SD}$ & Range \\
\hline $\begin{array}{l}\text { TREMATODA } \\
\text { Brachylaima } \text { sp. }\end{array}$ & small intestine & $\begin{array}{c}8.39 \\
(4.61-14.51) \\
\end{array}$ & $4.50 \pm 5.09$ & $14-1$ \\
\hline \multicolumn{5}{|l|}{ CESTODA } \\
\hline T. taeniaeformis & liver & $\begin{array}{c}11.89 \\
(7.28-18.62)\end{array}$ & $1.12 \pm 0.33$ & \\
\hline R. nana & small intestine & $\begin{array}{c}13.29 \\
(8.39-20.22)\end{array}$ & $4.84 \pm 10.32$ & $44-1$ \\
\hline H. diminuta & small intestine & $\begin{array}{c}24.48 \\
(17.85-32.50) \\
\end{array}$ & $3.54 \pm 5.40$ & \\
\hline \multicolumn{5}{|l|}{ NEMATODA } \\
\hline S. muris & large intestine & $\begin{array}{c}8.39 \\
(4.61-14.51)\end{array}$ & $64.58 \pm 61.92$ & $189-1$ \\
\hline H. spumosa & large intestine & $\begin{array}{c}82.52 \\
(75.08-88.16)\end{array}$ & $44.29 \pm 54.34$ & $247-1$ \\
\hline C. hepatica & liver & $\begin{array}{c}54.55 \\
(46.03-62.82)\end{array}$ & & \\
\hline N. brasiliensis & small intestine & $\begin{array}{c}18.88 \\
(13.02-26.46)\end{array}$ & $86.81 \pm 244.10$ & $1270-1$ \\
\hline Gongylonema sp. & stomach & $\begin{array}{c}4.90 \\
(2.16-10.21)\end{array}$ & $5.71 \pm 5.31$ & \\
\hline E. gastricus & stomach & $\begin{array}{c}30.07 \\
(22.84-38.39)\end{array}$ & $10.02 \pm 17.36$ & $102-1$ \\
\hline M. muris & stomach & $\begin{array}{c}30.77 \\
(23.47-39.12) \\
\end{array}$ & $5.39 \pm 5.70$ & \\
\hline $\begin{array}{l}\text { ACANTOCEPHALA } \\
\text { Acanthocephala } \mathrm{sp} .\end{array}$ & large intestine & $\begin{array}{c}0.70 \\
(0.04-4.42)\end{array}$ & $1.00 \pm 0.00$ & $1-1$ \\
\hline
\end{tabular}




\section{Discussion}

Data from previous studies on helminth parasites in Rattus norvegicus in Italy are only partially comparable with the helminth fauna in the present study due to misidentifications in previous works (e.g. T. pisiformis and $S$. obvelata are not parasites of the genus Rattus). The most relevant differences between our study and the papers by Macchioni (1967) and Vanni (1937) are the absence of Strongyloides ratti and Trichosomoides crassicauda, both common species in the helminth fauna of Rattus spp. in other European countries (Feliu et al., 1985a; Feliu et al., 1985b).

Our results show higher species richness (12) than in all previous recent studies worldwide (number helminth species - hosts analyzed): Abu-Madi et al. (2005) 1 - 179; Gomez-Villafane et al. (2008) 4 - 70; Rafineque et al. (2009) 6-49 and Waugh et al. (2006) $7-147$. Despite the fact that the number of analyzed hosts is correlated with species richness (Ribas et al., 2007), other factors also play a part in this species richness, as can be seen from previous studies in which no correspondence between sample size and number of helminth species was found.

The presence of $H$. diminuta should be noted since it has been reported in all the above-mentioned studies, which suggests a strong association between the host and this parasite.

A significant positive correlation was observed between both $\mathrm{P} \%$ and $\mathrm{MI}$, and the age of hosts and some helminths; but there was also a negative correlation in the case of Brachylaima sp. Similar results were found by GomezVillafane et al. (2008) in R. norvegicus in Argentina, with a not general pattern.

The study reveals a greater diversity of helminths than found in previous studies and adds to our knowledge of helminths in $R$. norvegicus.

\section{Acknowledgements}

This study was supported by the $60 \%$ programme of the Italian MIUR, University of Calabria (local coordinator: M. Cagnin) and by a project of the Istituto Zooprofilattico della Sicilia (IZS SI 008/00) (local coordinator: C. Di Bella). J.C. Casanova was supported by the Generalitat de Catalunya "2009 SGR 403”. A. Ribas was supported by grant n. 2008 BP A 0045 . We would like to thank G. Aloise for help during the trapping.

\section{References}

Abu-Madi, M. A., BehnKe, J. M., Mikhail, M., Lewis, J. W., AL-KAABI, M. L. (2005): Parasite populations in the brown rat Rattus norvegicus from Doha, Qatar between years: the effect of host age, sex and density. J. Helminthol., 79, 105 - 111. DOI: 10.1079/JOH2005274

Bush, A. O., Lafferty, K. D., Lotz, J. M., Shostak, A. W. (1997): Parasitology meets ecology on its own terms: Margolis et al. revisited. J. Parasitol., 83: 575 - 583. DOI: $10.2307 / 3284227$

CAlle, S. (1961): Parasitism by Capillaria hepatica. Pediatrics, 27 (4): 648 - 655

Delattre, P., Le LouARn, H. (1981): Dynamique des populations du rat noir, Rattus rattus, en mangrove lacustre. Mammalia, 45, 275 - 288. DOI: 10.1515/mamm.1981.45.3.275

Feliu, C., Mas Coma, S., Gallego, J. (1985a): Coneixements actuals sobre l'helminthfauna paràsita dels Múrids (Rodentia) a Catalunya. Bull. Inst. Catalana Hist. Natur., 50: $225-261$

Feliu, C., Torres, J., Gallego, J., Gosálbez, J., VenturA, J. (1985b): Primeros datos acerca de la helminthofauna de los Roedores del Delta del Ebro (Península Ibérica). Misc. Zool., 9: 55 - 64

Gomez-Villafañe, I. E., Robles, M. R., Busch, M. (2008): Helminth communities and host-parasite relationships in argentine brown rat (Rattus norvegicus). Helminthologia, 45: 126 - 129. DOI: 10.2478/s11687-008-0024-1 MACCHIONI, G. (1967): Indagine sulla elmintofauna dei muridi in Italia. Ann. Fac. Med. Vet. Pisa, 20: $40-51$

Mafiana, C. F., Osho, M. B., SAM-Wobo, S. (1997): Gastrointestinal helminth parasites of the black rat (Rattus rattus) in Abeokuta, southwest Nigeria. J. Helminthol., 71: 217 - 220. DOI: 10.1017/S0022149X00015947

Rafique, A., Rana, S. A., Khan, H. A., Sohail, A. (2009): Prevalence of some helminths in rodents captured from different city structures including poultry farms and human population of Faisalabad, Pakistan. Pak. Vet. J., 29(3): $141-144$

Ribas, A., Barbosa, A. M., Casanova, J. C., Real, R., FELIU, C., VARGAS J. M. (2007): Geographical patterns of the species richness of helminth parasites of moles (Talpa spp.) in Spain: Separating the effect of sampling effort from those of other conditioning factors. Vie milieu, 57(12): 49 - 56. DOI: $10.1079 / \mathrm{JOH} 2005328$

SARÀ, M. (1998): I mammiferi delle isole del mediterraneo. L'Epos Società Editrice, 163pp.

VANNI, V. (1937): Ricerche parassitologiche sui ratti di Roma. Ann. Ig. (Roma), 47, 477 - 492

Waugh, C. A., Lindo, J. F., Foronda, P., AngelesSantana, M., Lorenzo-Morales, J., Robinson, R. D. (2006): Population distribution and zoonotic potential of gastrointestinal helminths of wild rats Rattus rattus and $R$. norvegicus from Jamaica. J. Parasitol., 92(5): 1014 1018. DOI: $10.1645 / \mathrm{GE}-795 \mathrm{R} 1.1$ 